\title{
PELATIHAN: PENTINGNYA SOFT SKILL UNTUK KESUKSESAN KERJA BAGI SISWA-SISWI SEKOLAH MENENGAH KEJURUAN
}

\author{
Christine Winstinindah Sandroto \\ Fakultas Ekonomi dan Bisnis, Universitas Katolik Indonesia Atma Jaya \\ christine.wins@atmajaya.ac.id
}

\begin{abstract}
Training with the topic "The importance of soft skills in job success for Vocational High School students" is deemed necessary for preparation in entering the workplace. Besides hard skills, soft skills also play an essential role in work success. The training is packaged in a talk-show format via Instagram Live, which is considered relevant for Vocational High School students under supervised Bulir Padi. The material covered in this training includes: What are soft skills? The difference between hard skills?; The benefits of having soft skills at work; and how to improve soft skills. This activity in the form of training packaged in a talk show with Instagram Live media is carried out following the preparation and implementation stages. The evaluation stage is not carried out in a structured manner. Still, from the responses and questions that arise, we can conclude that the participants are interested in joining the talkshow enthusiastically. In the next training, if it is still in a covid-19 pandemic situation that does not allow face-to-face meetings at the same location, we will continue to apply training virtually either with the zoom application, google meet, or with Instagram Live. The training evaluation will be made more structured by distributing questionnaires to determine participant satisfaction with the training and conducting pre and post-test materials to assess participants' progress.
\end{abstract}

Keywords: job success, training, soft skills

\begin{abstract}
Abstrak
Pelatihan dengan topik “pentingnya soft skill bagi kesuksesan kerja bagi siswa-siswi Sekolah Menengah Kejuruan” dirasa diperlukan karena dalam persiapan memasuki dunia kerja. Selain hard skill, soft skill juga berperan penting untuk kesuksesan kerja siswa-siswi SMK binaan Bulir Padi. Pelatihan dikemas dalam format talk show via Intagram Live dipandang relevan bagi siswa-siswi SMK. Materi yang tercakup dalam kegiatan ini meliputi : apa itu soft skill? perbedaan dengan hard skill?; manfaat memiliki soft skill dalam bekerja; dan cara meningkatkan soft skill. Kegiatan pengabdian masyarakat dalam bentuk pelatihan yang dikemas dalam talk show dengan media Instagram Live dilaksanakan mengikuti tahap persiapan dan pelaksanaan. Tahap evaluasi tidak dilaksanakan secara terstruktur, namun dari respon dan pertanyaan yang muncul dapat disimpulkan bahwa peserta tertarik dan mengikuti talk show dengan antusias. Pada pelatihan selanjutnya, jika masih dalam situasi pandemi covid-19 yang tidak memungkinkan bertemu langsung secara tatap muka di lokasi yang sama, kami akan tetap menerapkan pelatihan secara virtual baik dengan aplikasi zoom, google meet, ataupun dengan Instagram Live. Evaluasi pelatihan akan dibuat lebih terstruktur dengan menyebarkan kuesioner untuk mengetahui tingkat kepuasan peserta terhadap pelatihan, serta melakukan pre dan post-test materi untuk mengetahui kemajuan peserta.
\end{abstract}

Kata kunci: kesuksesan kerja, pelatihan, soft skill

MARTABE : Jurnal Pengabdian Masyarakat | 298 


\section{PENDAHULUAN}

Kondisi di masa pandemi covid19 menghantam tidak hanya bidang kesehatan masyarakat, namun semua bidang terdampak karenanya, ekonomi, sosial, hingga pendidikan dan pelatihan. Namun kita tidak boleh berdiam diri, dan harus tetap terus mengupayakan inovasi dan kemajuan di berbagai bidang.

Sebelum masa pandemi covid19, pendidikan dan pelatihan dilaksanakan secara tatap muka dan semua pihak bertemu di lokasi tempat proses pembelajaran dilakukan. Tapi sekarang pendidikan dan pelatihan harus dilaksanakan secara kreatif, dilangsungkan secara virtual agar proses pembelajaran tidak terhenti karena pandemi covid-19 ini. Demikian pula dengan kegiatan pengabdian masyarakat yang selama ini dilaksanakan secara tatap muka, maka di masa pandemi covid-19 ini, kami berpikir keras bagaimana agar tidak terhenti.

Fakultas Ekonomi dan Bisnis, Universitas Katolik Indonesia Atma Jaya (selanjutnya disebut FEB-UAJ), selama ini melakukan kerjasama untuk kegiatan pengabdian masyarakat dengan banyak lembaga, dan salah satunya adalah dengan Yayasan Bulir Padi (selanjutnya akan disebut dengan Bulir Padi). Bulir Padi merupakan lembaga swadaya masyarakat yang mencurahkan dayanya untuk pendidikan anak-anak dari keluarga marginal di pinggiran Kota Jakarta dengan mendampingi mereka (www.bulirpadi.com, 2020). Salah satu bentuk pendidikan dan pelatihan yang dipandang penting adalah memberikan pelatihan pentingnya soft skill bagi kesuksesan kerja bagi siswa-siswi Sekolah Menengah Kejuruan (SMK) yang berada di bawah binaan Bulir Padi. Topik ini dirasa penting karena dalam persiapan memasuki dunia kerja selain hard skill, soft skill juga berperan penting untuk kesuksesan dalam kerja, sebagaimana menurut Paramita dalam Sandroto et al, 2018, mengemukakan bahwa statistik memperlihatkan keperihatinan dimana banyak lulusan SMK yang menjadi pengangguran (50\% dari lulusan SMK yang langsung mendapat pekerjaan, 1-2\% berwirausaha dan sisanya menganggur). Untuk itu pada era industri 4.0 ini, penduduk Indonesia diharapkan memiliki tingkat pendidikan yang tinggi, demikian juga hard skill dan soft skill (Sandroto, 2020). Dengan demikian, pemberdayaan masyarakat menjadi penguatan bagi masyarakat (Diwanti \& Dharma, 2019).

Untuk itulah pelatihan format talk show via Intagram Live mengenai pentingnya soft skill dalam dunia kerja dirasa penting dilakukan bagi siswasiswi SMK.

Adapun tujuan dari pelatihan dengan format talk show via Intagram Live ini adalah:

1. Berbagi inspirasi, wawasan dan pengalaman tentang apa yang sedang berkembang di masyarakat dengan nuansa kekinian yang dikemas secara informatif dan menyenangkan di masa pandemi covid-19.

2. Memberikan dan menyiapkan siswasiswi SMK di Jakarta untuk masuk didunia kerja, utamanya dalam soft skill.

3. Memperkenalkan dunia kampus kepada siswa-siswi SMK.

4. Menumbuhkan jiwa semangat belajar dan semangat keluar dari zona nyaman, agar tergerak untuk mempunyai kehidupan yang lebih baik dimasa depan.

5. Membangun relasi antar lembaga.

Peserta talk show adalah siswasiswi SMK di Jakarta yang bernaung di 
bawah pembinaan Yayasan Bulir Padi. Mereka ini adalah siswa-siswi SMK dari berbagai jurusan, diantaranya adalah IPS, IPA, Bisnis dan Manajemen, Administrasi Perkantoran, Pemasaran, Akuntansi, dan Teknik Kendaraan,.

\section{METODE}

Tahap-tahap kegiatan yang dilaksanakan adalah sebagai berikut ini:

\section{Tahap Persiapan}

Persiapan dilakukan selama 5 minggu, yang mencakup aktivitas :

a. Koordinasi pihak Bulir Padi dengan PIC dari FEB-UAJ melalui diskusi intens via chat whatsapp, telephone, dan email.

b. Melakukan training needs analysis dan pada akhirmya menyepakati bahwa topik yang perlu dibekali bagi siswa-siswi SMK adalah pelatihan pentingnya soft skill untuk mendukung kesuksesan kerja.

c. Menentukan jadwal pelatihan yang dapat disepakati bersama.

d. Menyiapkan materi pelatihan,

e. Memikirkan metoda pelatihan yang tepat di masa pandemic covid-19, dimana pelatihan secara tatap muka tidak memungkinkan. Dan disepakati pelatihan akan diselenggarakan dengan virtual dengan bentuk talk show via Instagram Live, dimana metoda ini juga dirasa relevan bagi siswa-siswi SMK.

\section{Tahap Pelaksanaan}

Pemaparan materi dilaksanakan Senin 27 Juli 2020. Metoda talk show dengan instagram Live dipandu/dimoderatori oleh Tia Sutresna (Founder dan Direktur Bulir Padi) dengan narasumber Christine Winstinindah Sandroto (Dosen FEBUAJ). Selama talk show, para peserta dapat mengajukan pertanyaan dengan menuliskan apa yang ditanyakan dalam chat room. Talk show ini sangat menarik dan yang seluruh penyampaian, baik moderator yang memandu, maupun narasumber menyesuaikan dengan kondisi anak bina.

\section{Evaluasi}

Tidak dilakukan secara terstruktur, namun tetap dibuat laporan kegiatan bersifat naratif.

\section{HASIL DAN PEMBAHASAN}

FEB-UAJ dan Bulir Padi telah menjalin kemitraan selama beberapa tahun. Berikut ini sekilas profil dari masing-masing pihak.

\section{Profil FEB-UAJ dan Bulir Padi}

Fakultas Ekonomi dan Bisnis, pada awal berdirinya pada 11 Juli 1960 bernama Fakultas Ekonomi (FE). FE merupakan fakultas yang pertama kali berdiri di Unika Atma Jaya. Pada mulanya $\mathrm{FE}$ hanya mempunyai satu jurusan, yaitu Manajemen, dengan program studi Ekonomi Perusahaan. Pada tahun 1974 dibuka jurusan Akuntansi, dan tahun 1992 dibuka jurusan Ilmu Ekonomi dan Studi Pembangunan. Saat ini program studi Strata 1 yang ada adalah Program Studi Manajemen, Program Studi Akuntansi, dan Program Studi IESP. (www.atmajaya.ac.id).

Bulir Padi, adalah sebuah organisasi nirlaba yang sudah berdiri sejak tahun 2002. Bulir Padi berkontribusi anak-anak kurang mampu di pinggiran Jakarta dengan memberikan beasiswa dan akses terhadap pendidikan. Tujuan yayasan ini adalah untuk memberdayakan anak bina agar dapat mandiri dan membantu peningkatan taraf hidup keluarga dan 
masyarakat

(https://www.bulirpadi.com/en)

\section{MATERI PELATIHAN}

Materi dalam kegiatan pelatihan kali ini meliputi :

\section{Definisi Soft Skill}

Definisi soft skill adalah keterampilan interpersonal, manusia, atau perilaku yang dibutuhkan untuk menerapkan keterampilan teknis dan pengetahuan di tempat kerja (Weber et al, 2011). Kechagias (2011) mengemukakan bahwa soft skill adalah keterampilan intra- dan interpersonal (sosio-emosional), penting untuk pengembangan pribadi, partisipasi sosial dan kesuksesan tempat kerja. Termasuk dalam soft skill diantaranya adalah keterampilan seperti komunikasi, kemampuan untuk bekerja dalam tim multidisiplin, kemampuan beradaptasi. Sedangkan, Laker dan Powell (2011) menjelaskan bahwa soft skill adalah keterampilan intrapersonal seperti kemampuan seseorang untuk mengelola diri sendiri serta keterampilan interpersonal seperti bagaimana seseorang menangani interaksi seseorang dengan orang lain.

\section{Perbedaan Soft Skill dan Hard Skill}

Rainsbury dalam Hendarman dan Cantner (2018) mengemukakan bahwa hard skill adalah keterampilan yang terkait dengan aspek teknik untuk melakukan tugas dalam pekerjaan dan sering dibahas dalam bagaimana cara pengetahuan diperoleh. Beberapa peneliti menggunakan konsep hard skill dalam keadaan manajemen tertentu secara kontekstual. Azim, et al (2010), mengemukakan bahwa hard skill biasanya merujuk pada konteks manajemen proyek sebagai proses, prosedur, alat dan teknik. Marando (2012) menggambarkan hard skill dalam manajemen proyek sebagai pembuatan hasil nyata seperti rincian kerja, jadwal kerja proyek, jalur lintasan kritis, laporan nilai yang diperoleh, anggaran proyek, dan sebagainya. Keterampilan ini lebih bersifat teknis, dan mereka sering menggabungkan penggunaan alat seperti penjadwalan proyek. Poisson-de Haro dan Turgut (2012) berpendapat bahwa hard skill yang terdiri dari keterampilan teknis dan keterampilan konseptual merupakan keterampilan penting bagi manajer.

Soft skill sebagian besar tidak berwujud, tidak terkait dengan hasil atau keluaran nyata. Menurut literatur, batasan antara konsep yang berkaitan dengan hard skill dan soft skill tidak selalu jelas. Menurut Rainsbury et al. (2002), hard skill terutama bersifat kognitif dan dipengaruhi oleh Intelligence Quotient (IQ) seseorang. Oleh karena itu, IQ merupakan pengukuran aspek kognitif. Dengan jangka waktu yang terbatas, ini dapat mengukur beberapa keterampilan seperti pemikiran konseptual dan pemecahan masalah. Poisson-de Haro dan Turgut (2012) mengklasifikasikan keterampilan konseptual sebagai hard skill. Sedangkan keterampilan memecahkan masalah, keterampilan membuat keputusan (Marando, 2012), dan keterampilan berpikir konseptual (Spencer \& Spencer 1993) dapat diklasifikasikan sebagai soft skill. Selain itu, keterampilan belajar dengan cepat (quick learning), seperti yang disebutkan oleh Martino et al. (2011) juga diklasifikasikan sebagai soft skill.

\section{Manfaat Soft Skill dalam Bekerja}

Soft skill sangat penting dalam keberhasilan karir karena banyak pekerjaan yang membutuhkan interaksi keterlibatan dengan pihak lain. Dengan demikian, kemampuan dalam berinteraksi dan berelasi adalah hal 
penting dalam dunia kerja. Soft skill dapat membuat seseorang mudah menyesuaikan diri dengan lingkungan, mengelola stres kerja, bekerja sama dalam tim dan mendorong relasi yang baik dengan rekan kerja, atasan, hingga pihak eksternal lainnya. Karyawan dengan soft skill yang baik, cenderung memiliki tingkat retensi lebih tinggi di tempat kerja daripada yang hanya mengandalkan hard skill saja. Keterampilan interpersonal yang baik juga akan bermanfaat saat menjalani proses wawancara kerja hingga mencapai keberhasilan dalam pekerjaan.

\section{Cara Meningkatkan Soft Skill}

Soft skill bukanlah sesuatu yang stagnan, tapi dapat diasah melalui pembelajaran dan pengalaman. Selagi masih menjadi siswa-siswi, sebaiknya mulai mengikuti berbagai kegiatan seperti ekstra kurikuler, seminar, kegiatan organisasi, dan lain sebagainya.

\section{EVALUASI PELATIHAN}

Metoda pelatihan dengan format talk show dengan Instagram Live, waktunya yang terbatas, membuat evaluasi pelatihan yang terstruktur tidak dilakukan. Namun dari banyaknya pertanyaan yang diajukan, bahkan banyak yang belum terjawab hingga waktu berakhir, menunjukkan bahwa peserta antusias mengikuti dan sangat ingin belajar banyak tentang soft skill yang dirasa akan sangat bermanfaat dalam dunia kerja yang akan mereka tekuni di tahun-tahun mendatang.

Setelah kegiatan selesai, narasumber membuat laporan kegiatan dan dilaporkan ke FEB-UAJ.
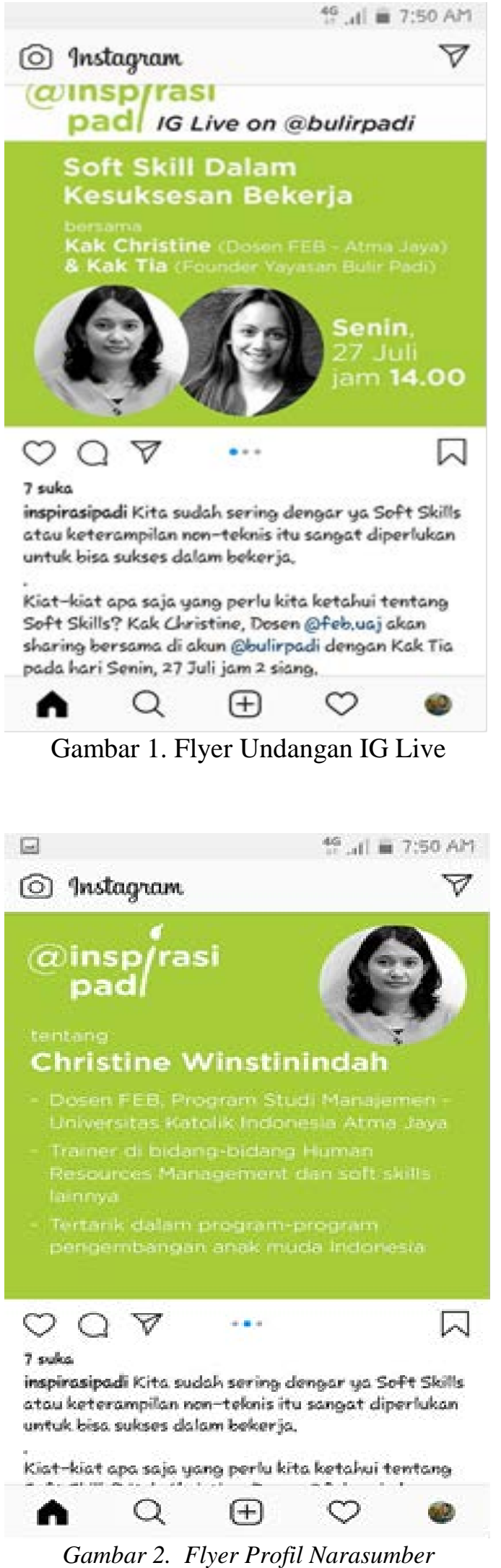


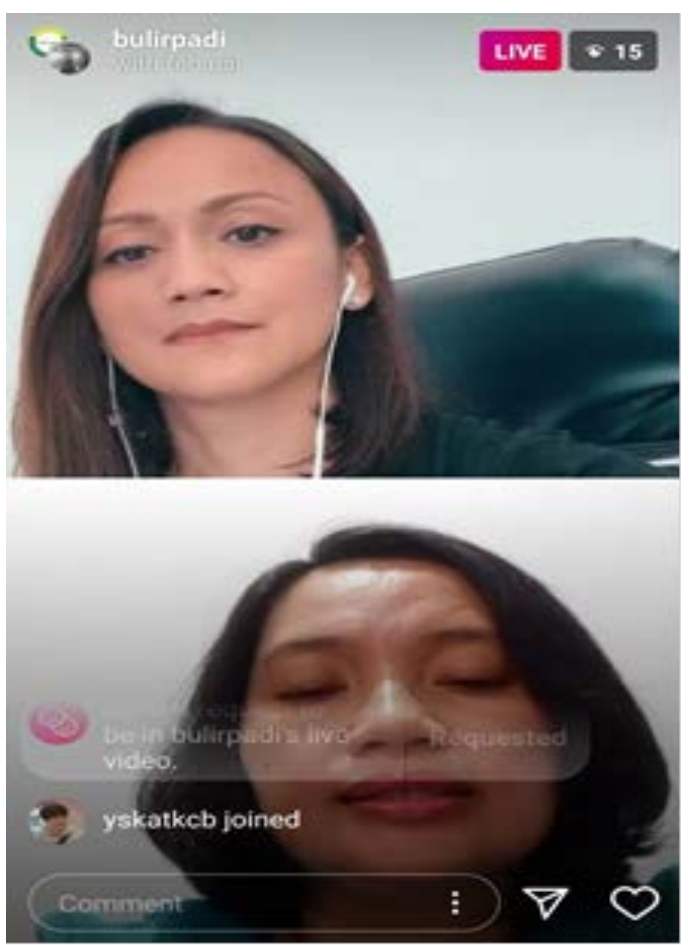

Gambar 3. Foto Screenshot saat IG Live

\section{HASIL DAN PEMBAHASAN}

Talk show via IG Live berjalan dengan lancar, karena baik moderator maupun narasumber sudah melakukan persiapan dengan baik dan didukung oleh koneksi internet yang lancar pada saat itu.

Sepanjang kegiatan, mendapatkan respon yang positif, walaupun jumlah peserta yang hadir tidak terlalu banyak, namun banyak sekali pertanyaan yang muncul yang mereka tuliskan dalam chat room. Ini menunjukkan mereka memperhatikan dan antusias dengan acara ini. Narasumber merasa senang dapat membagikan ilmu yang bermanfaat dan pihak Bulir Padi mengapresiasi narasumber dengan memberikan sertifikat.

\section{Kondisi Pelaksanaan yang Perlu Dievaluasi}

Terdapat beberapa kondisi dalam pelaksanaan pelatihan yang perlu dievaluasi, yaitu:
1. Metoda Instagram Live dirasa tidak lebih efektif dibandingkan bentuk virtual dengan menggunakan zoom atau google meet, karena moderator dan narasumber tidak bisa melihat para peserta dan ekspresi wajah selama talk-show. Selain itu materi juga tidak bisa ditampilkan di layar agar dapat dilihat oleh peserta.

2. Jumlah peserta yang hadir mengikuti talk show ini hanya separuh dari yang diharapkan hadir.

3. Peserta yang tidak hadir sulit dipastikan apakah terkendala tidak memiliki kuota internet dan peralatan pendukung ataukah memang siswasiswi SMK kurang memiliki kesadaran akan pentingnya topik ini untuk memasuki dunia kerja.

\section{Peningkatan untuk Kegiatan Pelatihan di Masa Mendatang}

Ke depannya metoda pelatihan yang dipakai akan lebih variatif. Jika pandemi covid-19 belum berakhir, talk show dengan Instagram Live akan tetap digunakan. Namun bisa juga dengan menggunakan aplikasi zoom, google meet atau lainnya yang memanfaatkan teknologi.

Yuwono et al, 2020, berpendapat bahwa di era digital saat ini, teknologi telah berkembang pesat dan memberi manfaat besar, termasuk di dalam dunia pendidikan. Google Form dapat dimanfaatkan sebagai media alternatif untuk mempersiapkan anak didik dalam menghadapi pengerjaan soal yang berbasis online dimana guru dapat membuat soal kuis dan ujian secara online.

Ke depannya, guna mengantipasi jika ada anak didik yang memiliki keterbatasan karena tuna rungu, maka penggunaan metode Addon (Linked) diharapkan dapat membantu anak tuna rungu wicara, 
namun tetap dengan pendampingan (Anggraini dan Hasnawati, 2020).

\section{SIMPULAN}

Kegiatan pengabdian masyarakat dalam bentuk pelatihan yang dikemas dalam talk show dengan media Instagram Live dilaksanakan melalui tahap persiapan dan pelaksanaan. Tahap evaluasi tidak dilaksanakan secara terstruktur, namun dari respon dan pertanyaan yang muncul dapat disimpulkan bahwa peserta tertarik dan mengikuti talk-show dengan antusias.

FEB-UAJ menyediakan narasumber yang menguasai topik, serta materi. Peserta adalah siswa-siswi SMK yang berada di bawah binaan Bulir Padi yang berada di Jakarta.

Dari diskusi dengan Bulir Padi, materi talk show yang disampaikan dirasa tepat dan sangat dibutuhkan karena dapat menunjang kesuksesan dalam bekerja.

Pada pelatihan selanjutnya, jika masih dalam situasi pandemi covid-19 yang tidak memungkinkan bertemu langsung secara tatap muka di lokasi yang sama, kami akan tetap menerapkan pelatihan secara virtual baik dengan aplikasi zoom, google meet, ataupun dengan Instagram Live. Evaluasi pelatihan akan dibuat lebih terstruktur dengan menyebarkan kuesioner untuk mengetahui tingkat kepuasan peserta terhadap pelatihan, serta melakukan pre dan post-test materi untuk mengetahui kemajuan peserta dengan membandingkan nilai yang diperoleh sebelum dan setelah pelatihan.

\section{UCAPAN TERIMA KASIH}

Penulis menyampaikan ucapan terimakasih kepada Fakultas Ekonomi dan Bisnis, Universitas Katolik Indonesia Atma Jaya atas segala dukungannya sehingga pengabdian kepada masyarakat ini dapat terselenggara dan Yayasan Bulir Padi, atas komitmennya terhadap pendidikan anak-anak dari keluarga kurang mampu di Jakarta.

\section{DAFTAR PUSTAKA}

Anggraini, Dwi., dan Hasnawati. 2020. Peningkatan Keterampilan Siswa Tuna Rungu Wicara dalam Menari Menggunakan Metode Add-On (Linked). MARTABE: Jurnal Pengabdian Masyarakat. 3(1).

Azim, S., Gale, A., Lawlor-Wright, T., Kirkham, R., Khan, A., \& Alam, M. 2010. The importance of soft skills in complex projects. International Journal of Managing Projects in Business. 3(3).

Diwanti, Dyah Pikanthi., dan Dharma, Andes Fuady. 2019. Pengembangan Potensi Masyarakat Bangunmulyo melalui Program I-Created (Inovasi, Kreatif dan Mandiri) Home Industri Salak Pondoh. MARTABE: Jurnal Pengabdian Masyarakat. 2(2).

Hendarman, Achmad Fajar., dan Cantner, Uwe. 2018. Soft Skills, Hard Skills, and Individual Innovatiness. Eurasia Business and Economics Society. 8.

Kechagias, K. 2011. Teaching and assessing soft skills. Thessaloniki (Neapolis): 1st Second Chance School of Thessaloniki, as part of the Measuring and Assessing Soft Skills (MASS) Project.

Laker, D. R., \& Powell, J. L. 2011. The differences between hard and 
soft skills and their relative impact on training transfer. Human Resource Development Quarterly. 22(1).

Marando, A. 2012. Balancing Project Management Hard Skills and Soft Skills. Rabb School of Continuing Studies: Division of Graduate Professional Studies, Brandeis University

Martino, G., \& Bartolone, J. 2011. Soft Skills for Open Innovation Success. In Paul Sloane (Ed), A guide to open innovation and crowd sourcing. Advice from leading expert. United Kingdom. Kogan page.

Poisson-de Haro, S., \& Turgut, G. 2012. Expanded strategy simulations: developing better managers. Journal of Management Development. 31(3).

Rainsbury, E., Hodges, D. L., Burchell, N., \& Lay, M. C. 2002. Ranking workplace competencies: Student and graduate perceptions.

Sandroto, Christine Winstinindah. 2020. Pelatihan Komunikasi dan Business Writing Bagi Anak Bina Lulusan SMU/SMK di Palmerah dan Bidaracina-
Jakarta. MARTABE: Jurnal Pengabdian Masyarakat. 3 (2).

Sandroto, Christine Winstinindah., Riyanti, Benedicta Prihatin Dwi., and Warmiyati, M.Tri. 2018. Entrepreneurial Intention and Competencies of Vocational and High School Graduates in Indonesia. Pertanika Journal Social Sciences \& Humanities. 26 (T).

Spencer, L. M., \& Spencer, S. M. 1993. Competency at work. New York: John Wiely \& Sons.

Weber, M. R., Crawford, A., Rivera, D., Jr., \& Finley, D. A. 2011. Using Delphi panels to assess soft skill competencies in entry level managers. Journal of Tourism Insights. 1(1).

Yuwono, Muhammad Ridlo., Ariwibowo, Eric Kunto., Firmansyah, Ferry., dan Indrayanto, Bayu. 2020. Pelatihan Anbuso, Zipgrade, dan Google Form sebagai Alternatif Penilaian Pembelajaran di Era Digital. MARTABE: Jurnal Pengabdian Masyarakat. 3(1).

https://www.atmajaya.ac.id https://www.bulirpadi.com/en 